Article

\title{
Saccharomyces cerevisiae Strain Diversity Associated with Spontaneous Fermentations in Organic Wineries from Galicia (NW Spain)
}

\author{
David Castrillo, Noemi Neira and Pilar Blanco * \\ Estación de Viticultura e Enoloxía de Galicia (EVEGA-AGACAL), 32428 Ourense, Spain; \\ david.castrillo.cachon@xunta.gal (D.C.); neira.022@gmail.com (N.N.) \\ * Correspondence: pilar.blanco.camba@xunta.gal; Tel.: +34-988788091
}

Received: 30 July 2020; Accepted: 14 September 2020; Published: 15 September 2020

check for updates

\begin{abstract}
Yeast play an essential role in wine quality. The dynamics of yeast strains during fermentation determine the final chemical and sensory characteristics of wines. This study aims to evaluate the Saccharomyces cerevisiae strains diversity in organic wineries from Galicia (NW Spain). Samples from spontaneous fermentations were taken in five wineries over three consecutive years (2013 to 2015). The samples were transported to the laboratory and processed following standard methodology for yeast isolation. S. cerevisiae strains were differentiated by mDNA-RFLPs. A total of 66 different strains were identified. Some of them presented a wide distribution and appeared in several wineries. However, other strains were typical from a specific winery. Similarity analysis using two different statistical tests showed significant differences in strain diversity among wineries. The results also revealed high biodiversity indexes; however, only some strains showed an important incidence in their distribution and frequency. Our findings confirmed that spontaneous fermentation favored the existence of a high S. cerevisiae strain diversity in organic wineries from Galicia. The presence of different yeasts during fermentation, specially winery-specific strains, contribute to increased wine complexity and differentiation.
\end{abstract}

Keywords: Saccharomyces cerevisiae; strains diversity; spontaneous fermentation; organic wineries

\section{Introduction}

Organic products are highly appreciated by consumers because they are healthier, and their production is more sustainable and respectful with the environment. The world's organic production is growing, but this increment is particularly significant in Spain where the global agricultural area dedicated to organic production has doubled in the last decade. The specific case of vineyards has seen an increase of 368\% [1]. These data consolidate Spain as the European Union country with the largest area of organic farming, leading the area of biological vineyard in the EU [2].

According to European Union regulations, the elaboration and labeling of organic wine require grapes from organic production, the use of authorized products and the respect of certain practices in the winery [3,4]. It is worth noting the obligation to use yeasts derived from organic raw materials [5]; in this sense, commercial strains of $S$. cerevisiae from organic production are already available in the market. However, the use of local yeasts is a practice that adds value to the final product. Several studies have shown that wines obtained by traditional methods of spontaneous fermentation are more appreciated by consumers for their structure and aromatic complexity [6]. In addition, the practices of organic cultivation and spontaneous winemaking favor the diversity of native yeasts [6-9].

The analysis of yeast populations dynamic during spontaneous fermentation by molecular techniques have shown a succession of genera, species, and strains, being Saccharomyces cerevisiae, a 
more ethanol-tolerant yeast, dominant in the final stages [10-12]. The wide number of yeasts involved in spontaneous fermentations own different phenotypic properties which influence the organoleptic properties resulting in more complex wines [13-16]. In addition, it is believed that the contribution of native yeasts imparts regional character to wines [17-20].

Numerous studies have examined and compared the S. cerevisiae population associated with vineyards, winery environment, and fermentation. The results evidenced the influence of several factors on the diversity of $S$. cerevisiae strains, including the use of commercial yeast, farming practices, vintage, grapevine varieties, and geography [21,22]. Regarding the impact of the use of commercial active dry yeasts (ADY) in the wineries, most studies reported that they reduced the diversity of indigenous S. cerevisiae population $[23,24]$. Moreover, some commercial strains became resident in the wineries; they were found at higher frequencies than indigenous ones $[25,26]$ and/or they were able to dominate spontaneous processes although they had not been inoculated [27-29]. Martiniuk et al. found that winery fermentations were dominated by a number of resident strains which genetically derived from commercial strains [8]. When the farming system was also considered, organic practices showed higher diversity, and some native strains were able to conduct fermentations [7]. Moreover, a recent study confirmed that the use of an autochthonous strain as a starter reduced the diversity whereas the inoculation of commercial strains did not [30].

The influence of geography on S. cerevisiae population has also been reported in vineyards and wineries from different countries such as Portugal [21,31,32], Italy [33,34], France [35,36], New Zealand [22,37,38], or Canada [8,25]. Most of these studies evidenced a correlation between S. cerevisiae strain and the oenological region, and they also showed a connection between the yeast communities present in the local environment, fermentations, and vineyards for each region [39]. Likewise, recent studies have revealed that the typical wine flavors and aromas of a particular region are due in part to the local microbial diversity known as microbial terroir [38,40-42].

Wine industry represents an important socioeconomic sector in Galicia (NW Spain). However, despite the boom of organic products, certified organic production is only applied in 83 ha of the approximately 25.200 ha of vineyards destined for wine elaboration in this region. Currently, 26 operators and 16 wineries are registered in the Regulatory Council of Organic Agriculture of Galicia [43]. The adverse orographic and climatic conditions of Galicia make organic practices in viticulture difficult.

Regarding characterization of yeast populations associated with vineyards and spontaneous fermentations in wineries from Galicia, little research has been published [44,45]. We have described the genetic diversity of $S$. cerevisiae strains in spontaneous fermentations and their prevalence in the environment at the experimental winery of Estación de Viticultura e Enoloxía de Galicia (EVEGA-AGACAL) $[27,46]$. In addition, Castrillo et al. reported a biogeographical pattern on the yeast diversity in organic and conventional grapes from different Denominations of Origin in Galicia [47]. The current study was carried out during 2013, 2014, and 2015 campaigns in order to evaluate the diversity of $S$. cerevisiae strains in some organic wineries from Galicia and to investigate the differences/similarities on yeast population between wineries.

\section{Materials and Methods}

\subsection{Wineries and Sampling}

This study was conducted during three consecutive vintages (2013 to 2015) at five wineries in Galicia (NW Spain). All wineries produce organic wines using the spontaneous fermentation technique, although in some of them, commercial yeasts have been employed occasionally. Table 1 summarizes the winery name and Denomination of Origin (DO) where it is included, and the number of fermentations sampled (white and red musts). 
Table 1. Wineries and fermentations sampled in this study.

\begin{tabular}{ccccc}
\hline Winery (Code) & $\begin{array}{c}\text { Denomination } \\
\text { of Origin (DO) }\end{array}$ & Vintages & \multicolumn{2}{c}{ Number of Fermentations } \\
\cline { 3 - 5 } & & 2 & White & Red \\
\hline Corisca (CO) & Rías Baixas & 3 & $3(3+1)$ & - \\
Diego de Lemos (DL) & Ribeira Sacra & 2 & $2(1+1)$ & $6(2+2+2)$ \\
Adega Beatriz (AB) $^{*}$ & Ribeiro & 3 & $8(1+1+6)$ & $6(1+1+4)$ \\
Pazo de Vieite (PV) & Ribeiro & 3 & $5(2+2+1)$ & $13(1+5+7)$ \\
Quinta da Muradella (QM) & Monterrei & 3 & \\
\hline
\end{tabular}

* Samples were taken only in 2013 and 2014. ${ }^{* *}$ Organic wine from Cooperativa Cume do Avia is produced in this winery.

Samples were taken randomly during the fermentation process in different tanks from each winery. However, some wineries were quite small, and few samples were picked. During the 2015 vintage 6 fermentations of white must and 4 fermentations of red must from Pazo de Vieite (PV) were monitored at different stages to follow the dynamics of $S$. cerevisiae population during the process. Representative fermentation samples were collected in sterile $100 \mathrm{~mL}$ bottles and transported to the laboratory.

\subsection{Sample Processing and Yeast Isolation}

Fermentation samples were serial adequately diluted (-4 and -5) and plated in duplicate on WL nutrient agar medium (Scharlau Microbiology), which allowed the differentiation among yeast species based on colony color [48]. The plates were incubated at $28{ }^{\circ} \mathrm{C}$ for two days. Then, those plates containing 25-250 colonies were used to isolate a representative number of colonies (20-30) from each sample. Yeasts were isolated in solid YEPD media ( $2 \% w / v$ glucose, $1 \% w / v$ yeast extract, $2 \% w / v$ peptone and $2 \% w / v$ agar) for further identification. In addition, Saccharomyces were confirmed by plating on Lysine Medium (Oxoid) where this type of yeasts is unable to growth [49].

\subsection{Identification of Saccharomyces cerevisiae Yeast Strains}

DNA from yeast isolates was extracted following the protocol described in Blanco et al. [46]. Differentiation of $S$. cerevisiae isolates at strain level was carried out by analysis of mitochondrial DNA restriction patterns (mtDNA-RFLPs) using the restriction endonuclease Hinf I [50]. Digestion reaction mix contained $16 \mu \mathrm{L}$ of total DNA, $2 \mu \mathrm{L}$ of Fastdigest Hinf I (Thermo Scientific) and $2 \mu \mathrm{L}$ of 10x Fastdigest Green buffer and were incubated at $37^{\circ} \mathrm{C}$ for $2 \mathrm{~h}$. Restriction fragments were separated by electrophoresis on $0.8 \%(w / v)$ agarose gels in TAE buffer ( $40 \mathrm{mM}$ Tris-acetate, $1 \mathrm{mM}$ EDTA) and visualized and photographed using the Molecular Imager ${ }^{\circledR}$ GelDocTM XR+(BIO-RAD) equipment for gel documentation.

\subsection{Determination of Yeast Killer Activity}

Killer activity of S. cerevisiae strains was tested using plates of YEPD medium buffered at $\mathrm{pH} 4.2$ with citrate-phosphate buffer and supplemented with $0.02 \%(w / v)$ methylene blue. S. cerevisiae CECT 1890 (sensitive strain), S. cerevisiae EX73 (positive killer strain) and EX33 (negative killer) [51] were used as controls.

Plates were seeded with $100 \mu \mathrm{L}$ of the sensitive strain as a lawn. Then, a patch of approximately $5 \mathrm{~mm}$ of diameter from solid cultures of strain being tested was added. The plates were incubated at $24{ }^{\circ} \mathrm{C}$ for $2-4$ days. Killer strains were surrounded by a clear growth inhibition halo of the sensitive strain.

\subsection{Data Analysis}

S. cerevisiae strain species diversity was estimated using classical ecology indexes. 
Shannon-Wiener index $\left(H^{\prime}\right)[52]$ was calculated as follows:

$$
H^{\prime}=-\sum_{i=1}^{S} p_{i} \ln \left(p_{i}\right)
$$

where $S$ is the strain richness (total number of strains found) and $p_{i}=n_{i} / N$ is the relative abundance of strains, calculated as the proportion of individuals $(n)$ of the strain $i$ with respect to the total of individuals $(N)$, based on the frequency of mtDNA-RFLPs. In this way, the index considers the number of strains present in the samples and their abundance.

Simpson's diversity index $(1-D)$ was used to evaluate yeast strain dominance, considering the probability that two randomly individual isolated yeasts in the fermentation samples belong to different species, and was calculated as follows [53]:

$$
1-D=1-\sum_{i=1}^{S}\left(p_{i}\right)^{2}=1-\left(\frac{\Sigma n(n-1)}{N(N-1)}\right)
$$

where $D$ is the Simpson's index, and $S$ and $p_{i}$ as described above.

Finally, in order to calculate the similarity or evenness of the different species abundance, a measure of Equitability (E) was calculated as follows [54]:

$$
E=H / \ln (S)=H / H_{\max }
$$

Equitability is 1 when there are similar proportions of all yeast species, but the value decreases when there are some rare and some common yeast species (very dissimilar abundance).

A hierarchical cluster analysis of $S$. cerevisiae strains found in the organic wineries was performed using the Ward method and data standardization. In addition, phylogenetic trees (dendrogram of distances type and constellation) were made to study the genetic relation between strains and their distribution with respect to the wineries in which they were identified. The software jmp 13 (SAS) was used for this purpose. Similarity and dissimilarity in S. cerevisiae strains between wineries were tested by one-way ANOSIM (non-parametric analysis of similarity) and one-way PERMANOVA (Permutational Multivariate Analysis of Variance Using Distance Matrices) applying the Bray-Curtis similarity matrix with the software PAST 3.20 (2018). These tests provide the probability of observing significant differences in yeast population between wineries by chance using permutations based on any distance measure, and to compare the abundance of different taxa (strains of $S$. cerevisiae from samples in the cellar) as well as the interaction between them [55-57]. In addition, the similarity percentages breakdown (SIMPER) between wineries was calculated to assess the average percent contribution of individual variables to the dissimilarity. Correspondence analysis (CA) was carried out by PAST 3.20 (2018) using the species frequencies to separate samples from different wineries.

\section{Results}

\subsection{Diversity of S. cerevisiae Strains in Galician Organic Wineries}

Considering all vintages, a total of 22 white grape fermentations and 27 red grape fermentations were sampled (Table 1), and 863 representative isolates were analyzed by mtDNA-RFLP (Table 2). Genetic characterization of the isolated yeasts allowed the identification of 66 different strains of S. cerevisiae. These strains were stored in EVEGA yeast collection and designed as $\mathrm{Rn}(\mathrm{n}=$ number in the EVEGA yeast collection).

The number of isolates and fermentations analyzed in each winery varied depending on the size of the wineries and the campaign. Both factors influenced the richness $(S)$ and diversity indexes obtained for each winery (Table 2). Thus, the lowest $S$ value was found in CO (6 strains; $\left.H^{\prime}=1.12\right)$, where only 4 tanks were sampled. Strain diversity in Diego de Lemos (DL) was slightly higher despite the fact that a larger number of tanks were sampled $\left(H^{\prime}=1.73\right)$ from both white and red wine fermentations 
during the three campaigns. In contrast, in Adega Beatriz (AB), 16 different strains of S. cerevisiae were identified, and the diversity value $\left(H^{\prime}=2.51\right)$ was higher than in $\mathrm{CO}$, although the same number of samples was collected. The number of tanks sampled in Quinta da Muradella (QM) and Pazo de Vieite (PV) was greater than in previous wineries. Therefore, the diversity found was higher (34 and 46 different strains; $H^{\prime}=2.70$ and 3.14, respectively). The higher diversity of strains found in PV was expected because, in this winery, some fermentations were sampled at different stages. The total value of $H^{\prime}=3.56$ indicated a high strain diversity in organic wineries from Galicia (Table 2). It was noteworthy the value of PV winery $\left(H^{\prime}=3.14\right)$, close to the $H^{\prime}$ total value.

Table 2. Diversity of S. cerevisiae strains in organic wineries from Galicia.

\begin{tabular}{ccccccc}
\hline \multirow{2}{*}{ Winery } & $\begin{array}{c}\text { Number of } \\
\text { Fermentations }\end{array}$ & $\begin{array}{c}\text { Isolates } \\
\text { Analyzed }\end{array}$ & & Richness * (\%) & \multicolumn{2}{c}{ Diversity Indexes } \\
\cline { 5 - 7 } & & & $S$ & $\boldsymbol{H}^{\prime}$ & $\mathbf{1 - D}$ & $\boldsymbol{E}$ \\
\hline Corisca & 4 & 27 & $6(9 \%)$ & 1.12 & 0.53 & 0.63 \\
Diego de Lemos & 9 & 80 & $8(12 \%)$ & 1.73 & 0.79 & 0.89 \\
Adega Beatriz & 4 & 42 & $16(24 \%)$ & 2.51 & 0.90 & 0.91 \\
Pazo de Vieite & 14 & 452 & $46(70 \%)$ & 3.14 & 0.94 & 0.82 \\
Quinta da Muradella & 18 & 262 & $34(52 \%)$ & 2.70 & 0.90 & 0.77 \\
\hline Total & 49 & 863 & $66(100 \%)$ & 3.56 & 0.96 & 0.85 \\
\hline
\end{tabular}

* Number of S. cerevisiae strains identified in each winery and percentage (\%) respect to the total number of strains.

\subsection{Occurrence of S. cerevisiae Strains in Different Wineries}

Some strains showed a wide geographical distribution, being common in wineries from different Denominations of Origin (Table S1, Figure 1). However, other strains appeared in a specific winery only. Thus, R7, R9, R14, and R46 strains were present in 4 of the 5 wineries evaluated. The genetic profile of R7 strain had already been identified in spontaneous fermentations in the EVEGA experimental cellar [46], and it was similar to that of a commercial yeast [27]. Accordingly, R7 was not found in the AB winery where commercial inoculums had never been used. R46 also showed wide distribution, with the exception of Ribeira Sacra winery (DL). R1, R15, and R71 appeared in three different wineries: R1 in DL, AB and PV; R15 and R71 in QM, AB, and PV.

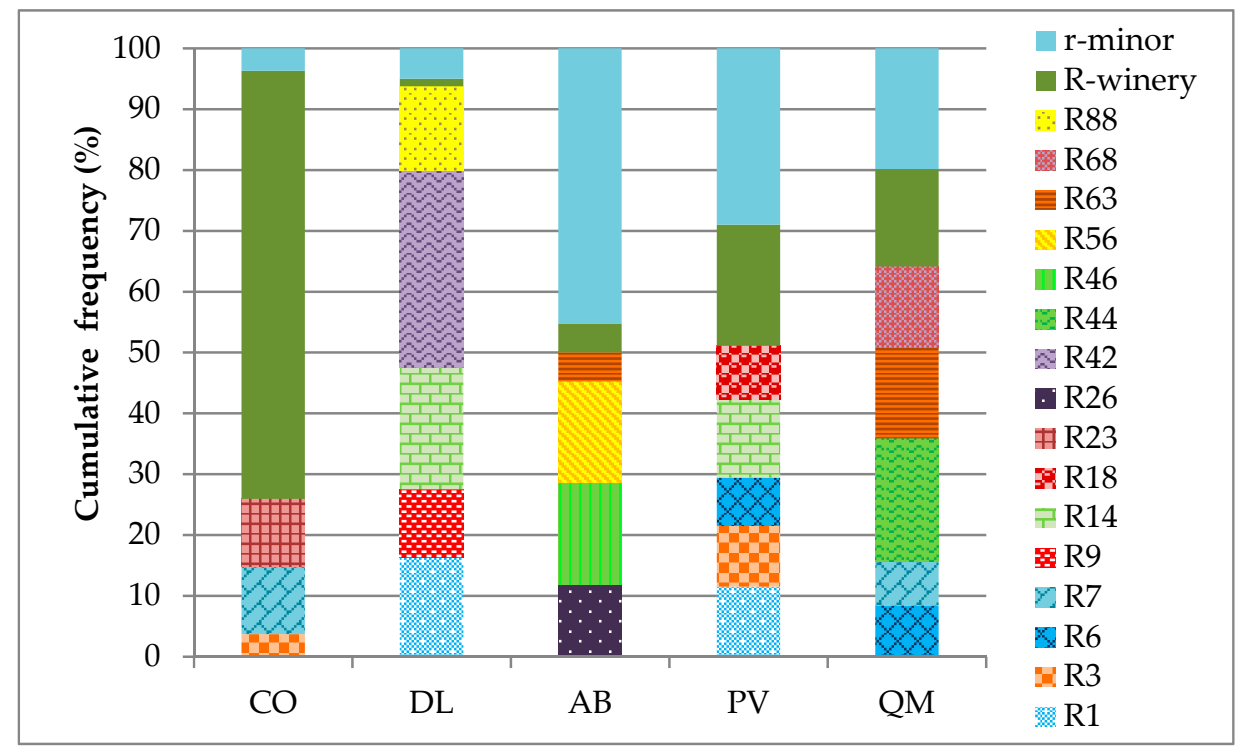

Figure 1. Cumulative frequency of Saccharomyces cerevisiae strains isolated from spontaneous fermentation in wineries from Galicia. R-winery: $\Sigma$ frequencies of specific strains in a winery; r-minor: $\Sigma$ frequencies of strains found at proportion $<5 \%$ in each winery. 
The other common strains were identified in two cellars, within the same or different DO: R25 and R42 in DL and PV; R3 and R23 in CO and PV; R6, R12, R16, R18, R21, R28, R31, R39, R41, R44, R45, R66 and R77 in QM and PV; R17, R26, R29, R40, R48 and R61 in AB and PV; R56 and R63 in QM and $\mathrm{AB}$ and R88 in QM and DL (Table S1).

A hierarchical cluster analysis was performed on the 66 strains of S. cerevisiae found (Figure S1 and Figure 2). The strains were grouped into five clusters. However, there was no genetic correlation between strains belonging to each winery. Strain genetic profiles gave information about the genetic similarity between them, but the groups observed were not related to the wineries where they had been isolated. Therefore, although in some wineries, there was a greater presence of some strains, a biogeographic pattern was not observed (Figure 2).

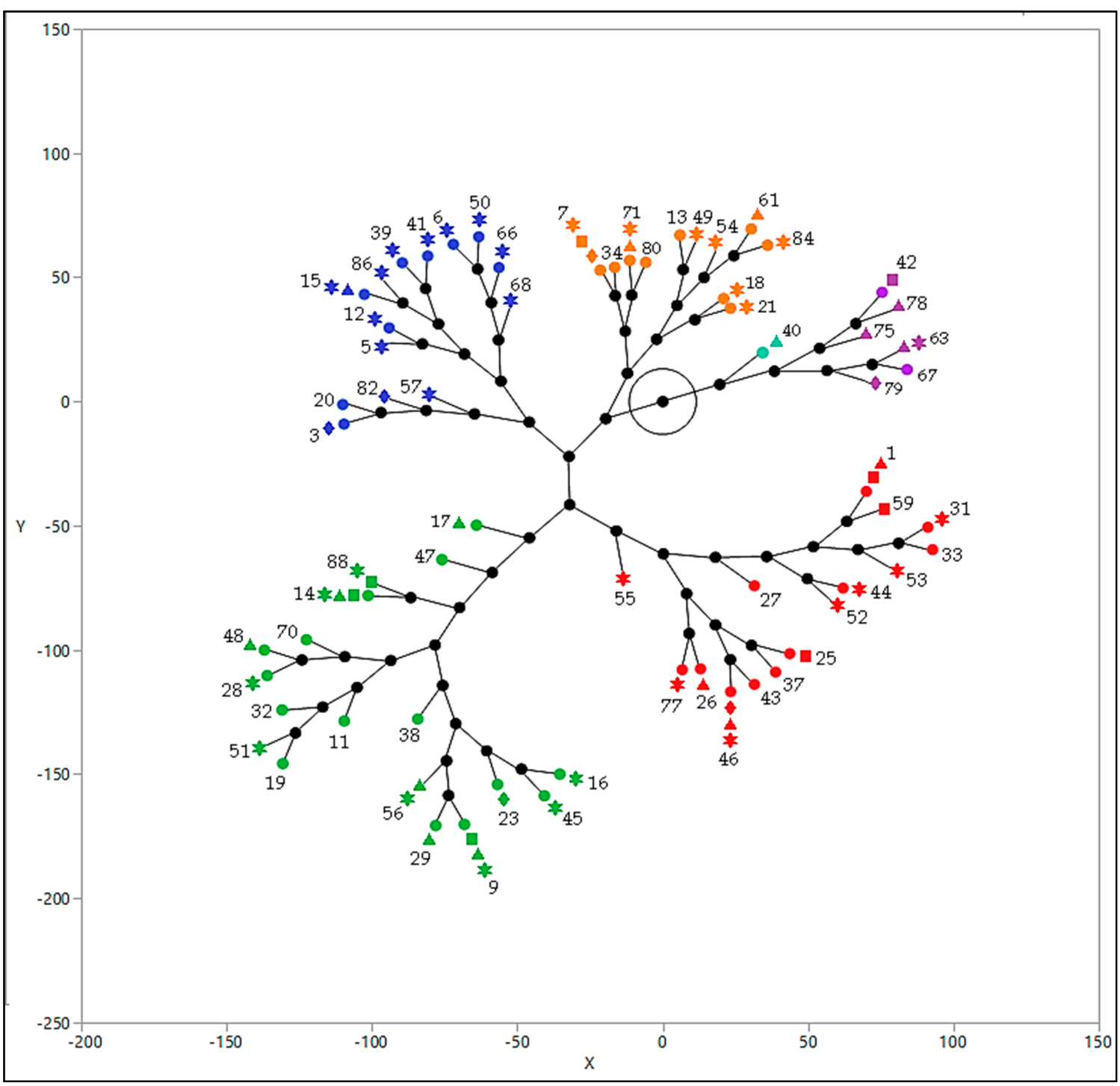

Figure 2. S. cerevisiae strains distribution in organic wineries from Galicia: phylogenetic tree in constellation formation. rhombus-CO; square-DL; triangle-AB; circle-PV; star-QM. 
In addition, the ability of these S. cerevisiae strains to secrete killer toxins was evaluated. It was observed that $59 \%$ of them were sensitive to killer toxin; 32\% strains were killer and the remaining $9 \%$ presented neutral killer phenotype (Table S1). The results indicated that the killer factor was not decisive in the distribution of the strains. In fact, strains R7 and R46, present in most samples, were sensitive; in contrast, other strains such as R79 and R82, identified only in CO, did have a killer ability.

The similarities-dissimilarities in the abundance of each strain with respect to the year and winery factors, as well as the interaction between them were analyzed by ANOSIM and PERMANOVA. The results of PERMANOVA $(F=3.781)$ and ANOSIM $(R=0.604)$ analyses showed very significant differences $(p=0.0001)$ for the yeast diversity between different wineries in the global analyses (Table 3). ANOSIM showed significant differences in the pairwise between PV and the remaining cellars (except $p_{\text {Corisca }}=0.066$ ). However, PERMANOVA test only found differences between PV-QM and PV-AB. The highest values of $\mathrm{R}$ and $\mathrm{F}$ were obtained in the Corisca winery with respect to all the others.

Table 3. Analysis of similarity-dissimilarity in the distribution of S. cerevisiae strains among the different wineries (ANOSIM and PERMANOVA).

\begin{tabular}{cccccccc}
\hline & \multicolumn{7}{c}{ Pairwise } \\
\hline ANOSIM & & & CO & DL & AB & PV & QM \\
\hline Permutation N & 9999 & CO & - & $\mathbf{0 . 9 1 6 7}$ & $\mathbf{1}$ & $\mathbf{1}$ & $\mathbf{1}$ \\
\hline Mean rank within & 26.13 & DL & 0.1037 & - & $\mathbf{0 . 3 3 3 3}$ & $\mathbf{0 . 4 4 4 4}$ & $\mathbf{0 . 3 7 0 4}$ \\
\hline Mean rank between & 57.83 & AB & 0.1002 & 0.1018 & - & $\mathbf{0 . 5 9 2 6}$ & $\mathbf{0 . 5 5 5 6}$ \\
\hline R & 0.604 & PV & 0.0662 & 0.0256 & 0.0296 & - & $\mathbf{0 . 5 5 5 6}$ \\
\hline$p$ (global; same) & 0.0001 & QM & 0.1045 & 0.1021 & 0.1008 & 0.0269 & - \\
\hline PERMANOVA & & & CO & DL & AB & PV & QM \\
\hline Permutation N & 9999 & CO & - & $\mathbf{4 . 2 7 2}$ & $\mathbf{1 1 . 3 8}$ & $\mathbf{1 3 . 3 7}$ & $\mathbf{7 . 9 0 9}$ \\
\hline Total sum of squares & 3.533 & DL & 0.0995 & - & $\mathbf{2 . 0 2 9}$ & $\mathbf{1 . 8 0 7}$ & $\mathbf{1 . 7 0 5}$ \\
\hline Within-group sum of squares & 1.406 & AB & 0.1003 & 0.102 & - & $\mathbf{2 . 7 7}$ & $\mathbf{2 . 6 2 3}$ \\
\hline F & 3.781 & PV & 0.0688 & 0.0813 & 0.0298 & - & $\mathbf{2 . 5 1 3}$ \\
\hline$p$ (global; same) & 0.0001 & QM & 0.0951 & 0.2008 & 0.0974 & 0.0285 & - \\
\hline
\end{tabular}

The values of the statistics $\mathrm{R}$ and $\mathrm{F}$ are shown in bold format, and the level of significance ( $p$-value) is shown in italic format.

In addition, SIMPER analysis allowed us to know the contribution of $S$. cerevisiae strains to diversity and the differences between wineries (Table S2). From all strains isolated 20 of them contributed almost $80 \%$ to global diversity. These major strains belonged to different wineries. S. cerevisiae R79 (only in the $\mathrm{CO}$ winery) was the strain mainly responsible for these differences among wineries, followed by R42, R14, R1, and R44. Correspondence analysis based on these strains allowed the separation of wineries in the biplot (Figure 3). Thus, $\mathrm{CO}$ winery was plotted in the negative part of axis1 mainly due to the presence of R79. The remaining wineries were located in the positive part of axis 1, DL, and PV in the positive part of axis 2. DL was associated with higher frequencies of R42, R88 and R9 whereas PV was characterized by the presence of R18, but also to R1 and R14 and R6. QM and AB were plotted in the negative part of axis 2: QM due to the frequency of strains R44, R63 and R68; AB associated with R46, R56, and R26. 


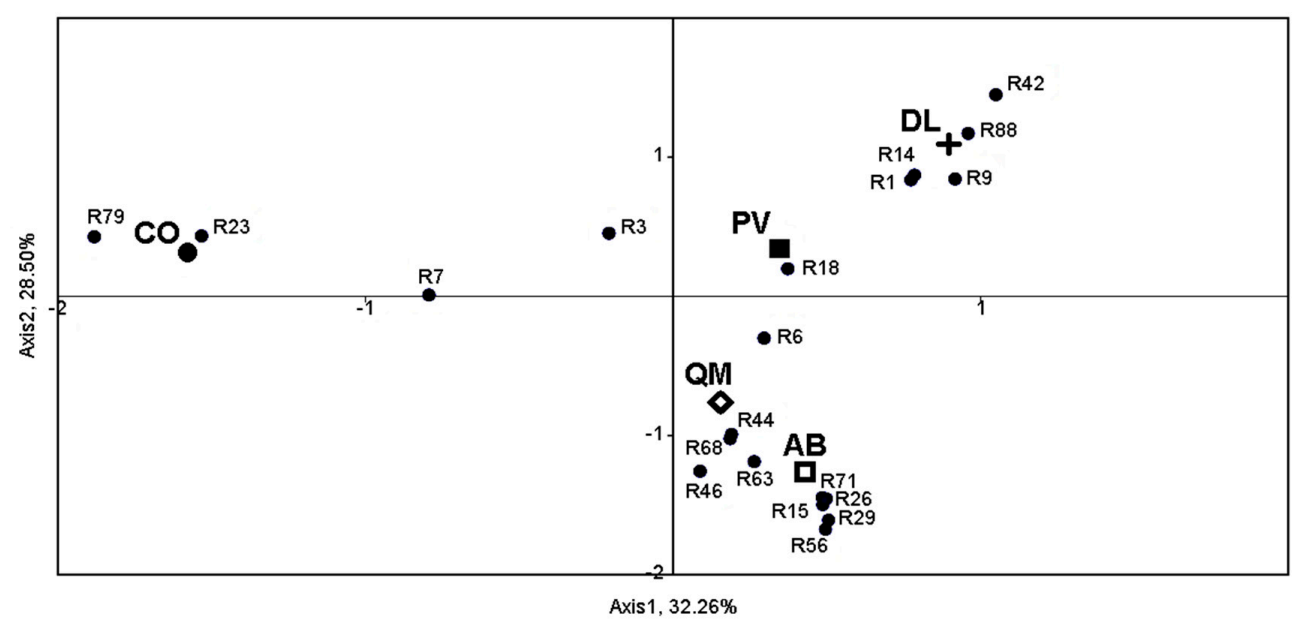

Figure 3. Correspondence analysis of the 20 main S. cerevisiae strains according to SIMPER in Galician organic wineries: biplot of the first two axes.

\subsection{Incidence of S. cerevisiae Strains per Campaign}

The total number of strains and the frequency of major strain for each campaign are summarized in Table 4. Despite the high diversity found, only a small number of strains appeared at relevant frequencies in different vintages, as mentioned above for wineries. In 2013, a total of 21 strains of S. cerevisiae were identified among all the wineries, but only 6 of them appeared with a frequency $>5 \%$. R79 reached $20 \%$ because it was the predominant strains in all fermentations evaluated in CO winery. In 2014, up to 38 different strains were found, with predominance of R68 and R88 (at 15\% and 17\%, respectively). Finally, in 2015 the diversity found was 54 strains, of which 7 appeared in a proportion greater than 5\%; R1 and R14 were the major strains, although they only achieved 10\% due the higher diversity of yeasts in this campaign (Table 4) compared to the previous ones. These major strains accounted for more than $60 \%$ of diversity found in 2015 and up to $75 \%$ in 2013 . Some of these strains as R79, R68, and R14 were killer yeasts. However, other dominant S. cerevisiae as R1, R6, and R88 were sensible strains (Table S1). Neutral yeast R44 was present in the three campaigns and was isolated at a significant frequency in the PV and QM wineries.

Table 4. Frequency of the main S. cerevisiae strains per campaign.

\begin{tabular}{cccc}
\hline Strain ${ }^{*}$ & \multicolumn{3}{c}{ Campaign } \\
\cline { 2 - 4 } & $\mathbf{2 0 1 3}$ & $\mathbf{2 0 1 4}$ & $\mathbf{2 0 1 5}$ \\
\hline R1 & 1.14 & 1.36 & 10.46 \\
R3 & 0.00 & 2.27 & 6.91 \\
R6 & 2.27 & 2.27 & 8.60 \\
R14 & 3.41 & 7.73 & 9.44 \\
R18 & 0.00 & 2.27 & 6.75 \\
R23 & 0.00 & 5.00 & 0.17 \\
R26 & 0.00 & 5.00 & 0.17 \\
R28 & 7.95 & 0.91 & 2.02 \\
R42 & 7.95 & 0.45 & 3.71 \\
R44 & 7.95 & 5.45 & 6.07 \\
R56 & 7.95 & 0.00 & 0.34 \\
R63 & 3.41 & 1.36 & 5.90 \\
R68 & 0.00 & 15.00 & 0.34 \\
R79 & 20.45 & 0.00 & 0.00 \\
R88 & 12.50 & 17.27 & 0.84 \\
\hline Total number of strains & 21 & 38 & 54 \\
major strains & 75.00 & 66.36 & 61.72 \\
\hline
\end{tabular}

* Strains found a frequency $>5 \%$. 
The analysis of similarities in the abundance of each strain with respect to the year by ANOSIM and PERMANOVA did not show significant differences between years for strain diversity $\left(p_{\text {PERMANOVA }}=0.849, \mathrm{~F}=0.707\right.$ and $p_{\text {ANOSIM }}=0.613, \mathrm{R}=-0.029$; data not shown $)$. When the year and winery factors were analyzed together, not significant results were obtained in the two-way ANOSIM (year factor: $p=0.505, \mathrm{R}=1$; winery factor: $p=0.199, \mathrm{R}=1$ ). However, significant differences were found when two-way PERMANOVA was applied: year factor: $p=0.047, \mathrm{~F}=1.878$; winery factor: $p=0.044, \mathrm{~F}=3.762$; interaction: $p=0.044, \mathrm{~F}=1.866$. These differences between ANOSIM and PERMANOVA results are observed when the factor is not strong enough. Therefore, our findings suggest that the effect of year factor on strain diversity is weaker than the winery factor.

\subsection{S. cerevisiae Population Dynamics during Fermentation}

The study of population dynamics evidenced the presence of several strains of S. cerevisiae during all stages of fermentation in PV winery in 2015. In total, 31 strains were identified in white must fermentations: 17 strains in must, 15 strains at initial stages, 20 strains in tumultuous stage and 18 at the end of the process. Red grapes fermentations involved 24 different strains of S. cerevisiae: 18 and 19 in tumultuous and final stages, respectively. From all of them, only few strains appeared at frequency $>10 \%$, fermenting in co-dominance (Figure 4). The dominant yeasts were R1, R3, R6, and R14 in white must fermentations. However, in red grapes, the relevant strains were R1 and R18, and R14 at final stage of fermentations.

Furthermore, a sequential substitution of yeast strains during the fermentation process was observed. For instance, strains R6 and R13 appeared in Ft in red fermentations but not at the end. In contrast, R14 increased its frequency in the final stages of fermentation.

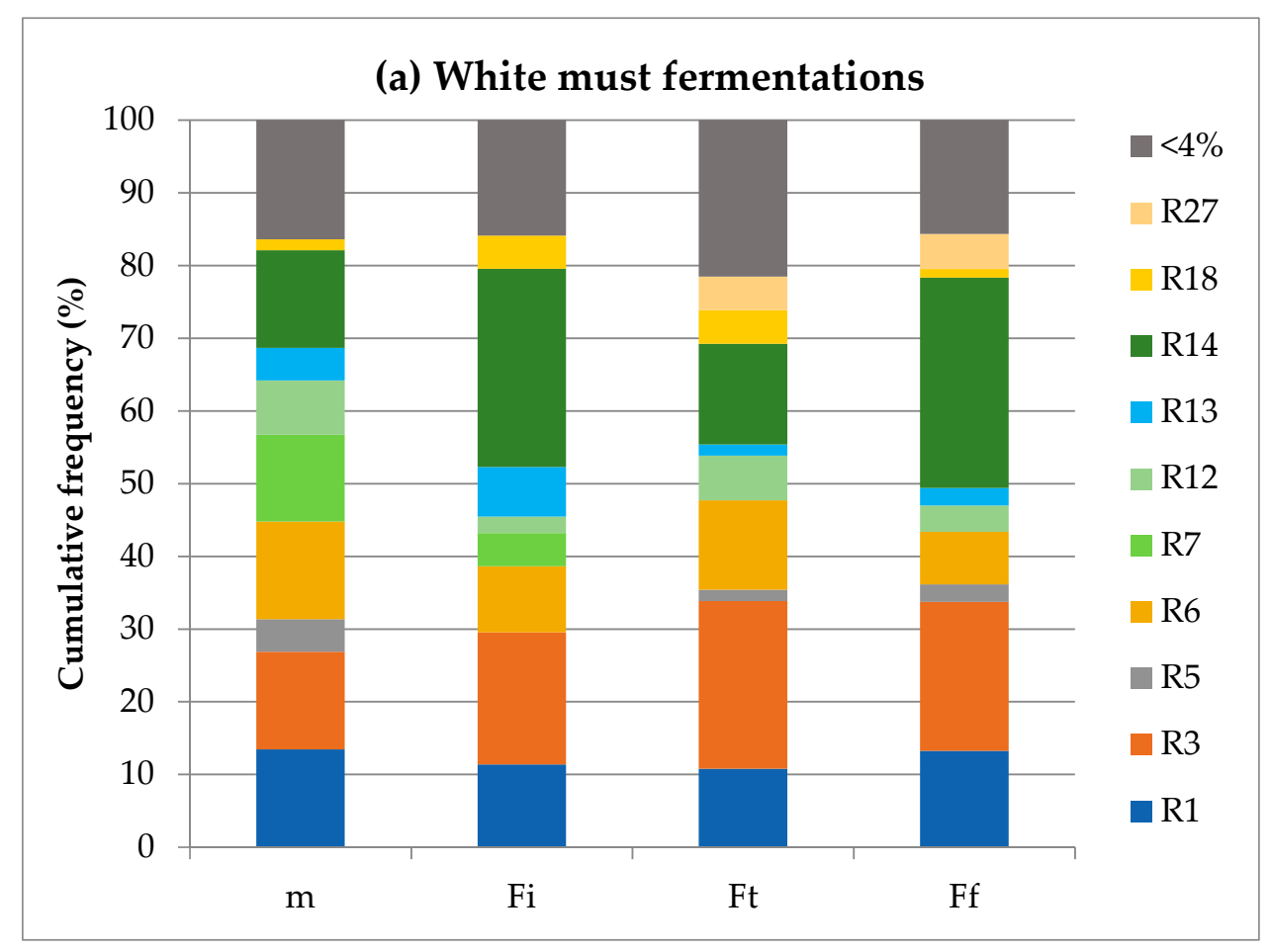

Figure 4. Cont. 


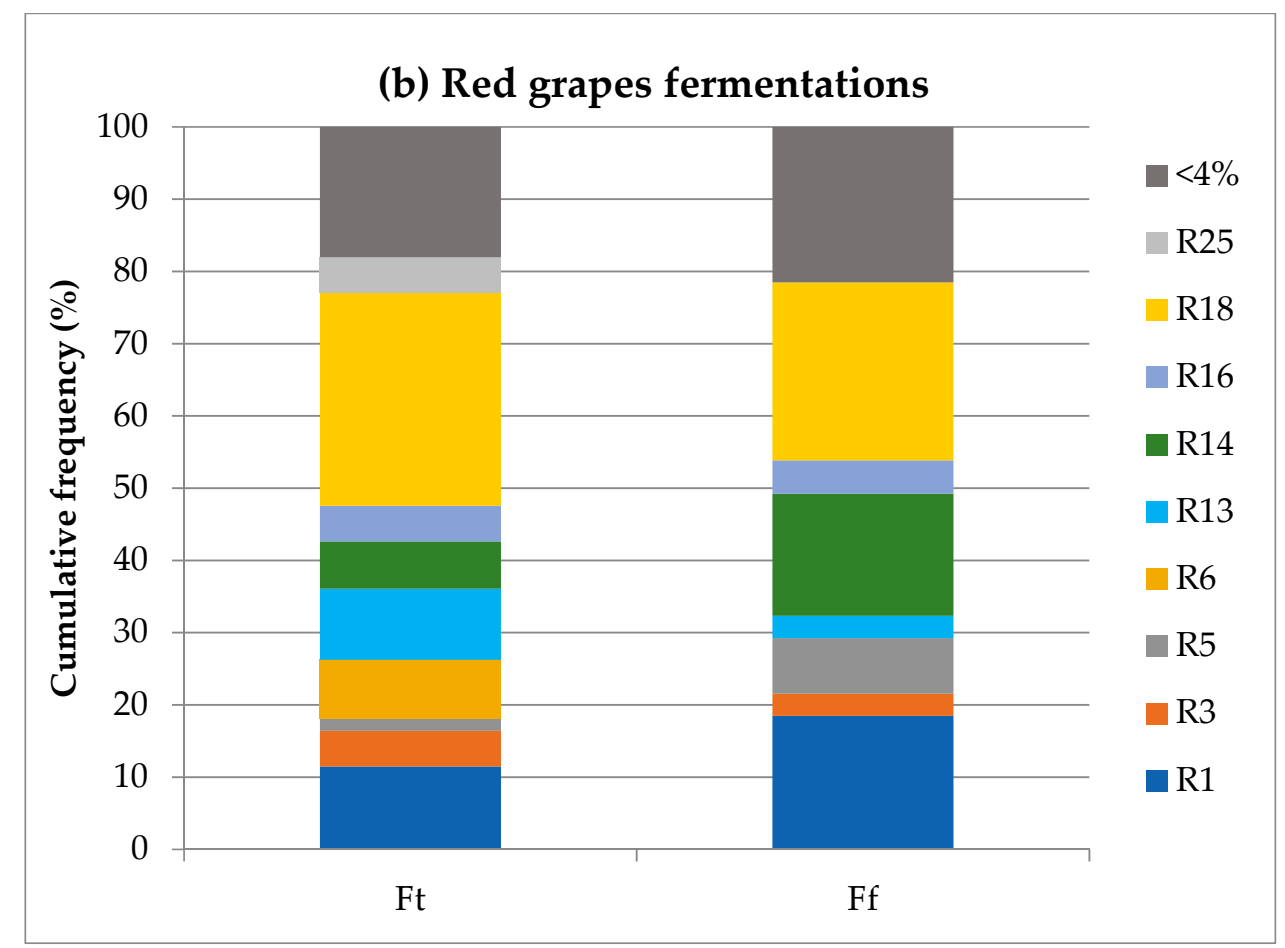

Figure 4. Dynamic of S. cerevisiae strains population during 2015 white must (a) and red grapes (b) fermentations in Pazo de Vieite. m-must; Fi, Ft, and Ff-initial, tumultuous and final stages of fermentation. $<4 \%-\sum$ frequencies of those strains that appeared at frequencies $<4 \%$.

\section{Discussion}

The diversity and dynamics of yeast population during fermentation is influenced by several factors including farming practices, geography, vintage, interaction among yeast species, and the use of commercial ADY in the wineries, among others. In this study, the diversity of $S$. cerevisiae strains was studied in five organic commercial wineries from different Denominations of Origin within Galicia (NW Spain). These wineries produce organic wines by spontaneous fermentation.

The results showed a high diversity of $S$. cerevisiae strains (66 different strains), although with variations among wineries. It should be mentioned that some of these strains could be hybrids involving S. cerevisiae strains due to the limitation of mtDNA-RFLPs technique to distinguish species within Saccharomyces genus. The differences found were expected since the amount of fermentation evaluated, and the number of isolates obtained in each winery varied depending on the size of the wineries and the campaign (Table 1). The lowest richness $(S)$ value was obtained in Corisca (CO); in this winery only 4 tanks were sampled, all of them fermentations of white Albariño must and only from two different vintages. Diego de Lemos (DL) also presented a low diversity of strains despite the fact that a larger number of tanks were sampled, including both white and red wine fermentations during the three campaigns (Table 2). DL produced the first wines certified as organic in Galicia (in 2002) using spontaneous vinifications; it is possible that autochthonous resident yeasts well adapted to the winery environment are implanted in the fermentations year after year, imposing themselves over those that enter with the grape. This behavior has been observed in the EVEGA experimental winery [27] and by other authors [9]. Similarly, de Celis et al. reported that the recurrent use of an autochthonous strain reduced the diversity of $S$. cerevisiae strains in a winery, probably due to a good adaptation of these strains to environmental conditions [30]. In contrast, the yeast diversity found in Adega Beatriz $(\mathrm{AB})$ was high compared to $\mathrm{CO}$, although the same number of samples was collected. These results can be explained because despite being very small, AB produced both white and red wines and commercial yeasts were never introduced in the winery. Regarding Quinta da Muradella $(\mathrm{QM})$ and Pazo de Vieite (PV), the number of tanks sampled was greater than in previous wineries. 
Therefore, the diversity values obtained were higher (34 and 46 strains, respectively), as expected. However, between these two wineries, PV showed a higher number of strains (despite the fact that a lower number of fermentations were sampled) because several samples per fermentation were taken to follow the dynamic of yeast population during the process (Figure 4). The limited studies focused on yeast diversity in organic wineries described up to 108 different genotypes comparing organic and conventional fermentations; organic farming benefited the diversity and abundance of yeast [7]. Recently, a similar approach including wineries under both farming systems, reported higher diversity under conventional production [30]. In our study, only organic wineries were evaluated, so we cannot establish this type of comparison. As an exception, in Pazo de Vieite (PV) conventional vinifications were also performed using ADY, but the results suggested that this fact did not affect the diversity of yeast population during organic spontaneous fermentations. Previous studies carried out in the EVEGA experimental cellar with conventional spontaneous fermentations reported 19 different strains out of a total of 446 isolates [46].

The yeast diversity values observed in Galician organic wineries were close to those reported in other studies. Thus, Morgan et al. also identified 66 unique strains in two Canadian wineries, 45 and 32 strains in each winery evaluated, respectively [26]. Similarly, Scholl et al. found 59 different strains in three wineries [25]. However, in studies involving different vineyards, campaigns and both natural and fermentations at winery scale it was observed a higher diversity of S. cerevisiae population [8]. In Spanish wineries, de Celis et al. described important differences in the S. cerevisiae diversity (from 1 to 151 strains) among wineries related to farming system or the use of commercial or autochthonous yeasts [30]. Other authors using mtDNA-RFLPs found until 38 different profiles in wineries from La Rioja [24]; whereas up to 112 strains were distinguished in two wineries in three vintages in Cataluña using the same methodology [58].

The total value of $H^{\prime}=3.56$ indicated a high strain diversity in organics wineries from Galicia (Table 2). It was remarkable the value of PV winery $\left(H^{\prime}=3.14\right)$, close to the $H^{\prime}$ total value, probably due to the fact that in this winery, some fermentations were sampled at different stages as mentioned above. The results obtained for individual wineries were similar or slightly superior to those reported for S. cerevisiae strain diversity in other studies under organic production in Spain [7,30,59]. Much higher values $(H=6.22)$ were achieved when more robust molecular techniques were used, and sweet wine and long term period of study were included [60]. A high diversity of S. cerevisiae strains was also observed in two regions in Portugal [32] and in New Zealand [37] using microsatellites.

Regarding the impact of the use of commercial yeasts at wineries, most studies reported that ADY reduced the diversity of indigenous $S$. cerevisiae population [23,24]. Moreover, some commercial strains became resident in the wineries, they were found at higher frequencies than indigenous ones, even they were able to direct spontaneous processes although they had not been inoculated [25,26,28]. For instance, R7 strain had already been identified in spontaneous fermentations in the EVEGA experimental cellar [46], and its genetic profile was similar to that of a commercial yeast [27]. Accordingly, R7 was not found in the AB winery where commercial inoculums had never been used. Other authors reported that despite the predominance of commercial winey-resident yeasts, some local strains were able to conduct fermentations up to the end [7]. Further genetic analysis has evidenced that some new strains well adapted to the local environment derived from commercial strains [8] as suggested by Viel et al. [34]. In contrast, in certain studies, the impact of ADY on spontaneous fermentations was inexistent $[37,61]$. Furthermore, de Celis et al. observed that the use of autochthonous inocula reduced the diversity of $S$. cerevisiae strains, whereas allochthonous commercial strains did not [30].

The genetic analysis grouped the 66 strains of $S$. cerevisiae into five clusters (Figure 2), but a genetic correlation between strains belonging to each winery could not be established. Similarly, a biogeographic pattern considering the genetic profiles was not clearly observed in other studies [7,36,62]. However, ANOSIM and PERMANOVA results based on the number and abundance of $S$. cerevisiae strains in each winery evidenced significant differences among them (Table 4). Very significant differences were also found by PERMANOVA in the S. cerevisiae population between wineries in 
Canada [25]. In addition, SIMPER analysis of data showed that 20 strains contributed almost $80 \%$ to global diversity. These strains allowed the separation of wineries by correspondence analysis (Figure 3 ) due to the presence and proportion of certain yeast strains. Several factors could have contributed to these differences, including must composition, winemaking practices (grape processing, fermentation protocols, temperature), ethanol tolerance of strains, and even the killer factor [63,64]. It is believed that the ability of $S$. cerevisiae strains to secrete killer toxins could facilitate their prevalence in the medium and their dominance during fermentation [65]. However, in this study most strains (59\%) were sensitive, indicating that the killer factor was not decisive in the distribution of the strains. In fact, strains R7 and R46, present in most samples, were sensitive; in contrast, other strains such as R79 and $\mathrm{R} 82$, identified only in $\mathrm{CO}$, did have killer ability and they appeared at high frequency. Cocolin et al. found limited killer activity in S. cerevisiae population from an abandoned old winery but higher presence of killer yeast in a modern winery, indicating the role of this ability in strain selection [66]. Indeed, in inoculated fermentations the use of killer S. cerevisiae strains can help to suppress the wild yeasts. In this sense, their effect depended on factors such as the initial ratio of killer to sensitive strains, the environmental conditions, the susceptibility of sensitive strains to the killer toxins, the inoculum size and nitrogen availability [65].

Regarding strain distribution, our results confirmed the presence of certain strains in all wineries. The wide geographical distribution of a strain indicates a good adaptation to must characteristics of different areas as well as to the winery's environment. Some studies confirmed that these resident yeasts are responsible for spontaneous fermentations in the winery [27,67]. Moreover, humans, insects, or birds could be responsible for this transport of strains among different cellars [22]. Despite the major strain widely distributed, we also found a large number of minor strains, some of them were specific for a particular winery. Other authors also described a different composition of $S$. cerevisiae strains for each winery in studies conducted on spontaneous fermentations [25,62]. Drumonde-Neves et al. reported the influence of geography over ecology in the differentiation of S. cerevisiae population in the Azores Archipelago [21]. Recent studies revealed that the predominant S. cerevisiae strains isolated from different wineries in the same region could be very similar, highlighting a correlation between the strain and the oenological region $[38,68]$. These findings have also been associated with the existence of a microbial terroir, which postulates flavors and aromas in wine typical of a particular region [41]. Supporting this idea, Drumonde-Neves et al. described a phenotypic differentiation of S. cerevisiae population from different locations [21]. Indeed, spontaneous fermentations involve numerous strains with different phenotypic properties, which, in proportion to their relative abundance, influence the aromatic properties of the wine $[13,14,16]$.

The evaluation of $S$. cerevisiae strains distribution in different vintages showed that only a small number of strains appeared at relevant frequencies $(>5 \%)$ despite the high diversity found. All of them were isolated during at least two or three campaigns, except R79 (isolated only in CO in 2013) (Table 4). The analysis of similarity of yeast diversity (PERMANOVA) showed significant differences when both factors (year and wineries) were analyzed together but not when only the year factor was considered alone. These results suggested that the year factor is weak. Besides, it was shown by SIMPER analysis that these strains were the main contributors to global diversity (Table S2). The persistence of certain yeast in a winery or region was previously reported $[27,28]$. In contrast, other authors found that the vintage effect overcomes the terroir [69].

During fermentation, there is a sequential succession of yeast species and $S$. cerevisiae strains $[7,11,24]$. However, only few of them are capable of dominating the final stages of the fermentative process. Dominant strains are those that comprise $10 \%$ or more of the relative abundance during fermentation, so they have an impact on organoleptic properties of wine [70]. Despite the high diversity found in this study, only few strains reached this percentage for each winery or campaign (Figure 1 and Table 4). The results also showed that several strains of S. cerevisiae appeared in almost all samples acting in co-dominance (Figure 4). Several authors have reported that strain richness tended to be greater in the mid and final stages than in the early stage of fermentation $[7,28]$; accordingly, our 
results showed similar richness or slightly lower in musts and Fi than at the end of fermentation. In addition, we observed differences in the yeast population between red and white must fermentations (Figure 4). These differences could be expected since both substrates differ in their characteristics and fermentation protocols $[25,58,63]$. In addition, the interaction of $S$. cerevisiae and other yeast species in must also influence yeast population dynamics during fermentation. The presence of different yeast species and strains contributes to increase wines complexity and differentiation $[7,19,27]$. Furthermore, the presence of local strain in a winery encourages the differentiation and typicality of its wines. Thus, the sensory analysis of Galician wines showed that tasters distinguished organic wines from conventional ones. Furthermore, organic wines were better rated in some cases [71]. Accordingly, Callejon et al. also reported better organoleptic properties in organic wines obtained with autochthonous yeasts [72] and Blanco et al. described that wines from spontaneous processes were the most preferred by tasters [73].

\section{Conclusions}

The results obtained in this study evidenced that spontaneous fermentation of organic musts favors the diversity of $S$. cerevisiae strains during the winemaking process. Despite the high diversity of strains, only some of them had a significant incidence in distribution and frequency. In addition, some strains had a wide distribution and were common to several wineries. However, other strains were specific for a particular winery. The presence of different yeasts during the fermentation process contributes to increasing the complexity of the wines and, therefore, to their differentiation.

Supplementary Materials: The following are available online at http://www.mdpi.com/2311-5637/6/3/89/s1. Table S1: Frequency (\%) of Saccharomyces cerevisiae strains found in each winery and killer activity, Figure S1: Dendrogram of distances; phylogenetic tree of the 65 autochthonous strains of $S$. cerevisiae identified during spontaneous fermentations. Table S2: Contribution of the twenty predominant S. cerevisiae strains (obtained by SIMPER analysis).

Author Contributions: P.B. and D.C. conceived and designed the experiments and took the samples to control fermentations. N.N. carried out the microbiological and genetic control in the laboratory; P.B. and D.C. analyzed the data; wrote and critically revised the manuscript before submission. All authors have read and agreed to the published version of the manuscript.

Funding: This research was funded by Instituto Nacional de Tecnología Agraria y Alimentaria (INIA) grant number RTA2012-00021-C03-01 and cofinanced with FEDER funds (European Regional Development Fund).

Acknowledgments: David Castrillo thanks to INIA and European Social Fund for his FPI predoctoral contract. We are grateful to Corisca, Diego de Lemos, Cooperativa Cume do Avia, Adega Beatriz, Pazo de Vieite, and Quinta da Muradella for their collaboration allowing us to collect samples from their wineries.

Conflicts of Interest: The authors declare no conflict of interest.

\section{References}

1. MAPA (Ministerio de Agricultura y Pesca). Agricultura Ecológica, Estadísticas 2018; MAPA: Madrid, Spain, 2019; pp. 1-175.

2. Willer, H.; Lernoud, J. The World of Organic Agriculture. Statistics and Emerging Trends 2018. Fibl, Fricks, and Ifoam-Organics International; Research Institute of Organic Agriculture (FiBL): Frick, Switzerland; IFOAM Organics International: Bonn, Germany, 2018; ISBN 9783037360675.

3. Council of the European Union Commission regulation (EC). No 889/2008 of 5 September 2008 laying down detailed rules for the implementation of Council Regulation (EC) No 834/2007 on organic production and labelling of organic products with regard to organic production, labelling and control. Off. J. Eur. Union 2008, 250, 1-84.

4. Council of the European Union Council Regulation (EC). No 834/2007 of 28 June 2007 on organic production and labelling of organic products and repealing Regulation (EEC) No 2092/91. Off. J. Eur. Union 2007, 189, $1-23$.

5. Council of the European Union Commission regulation (EC). No 203/2012 of 8 March 2012 determining rules on organic wine production. Off. J. Eur. Union 2012, 71, 42-47. 
6. Blanco, P.; Mirás-Avalos, J.M.; Suárez, V.; Orriols, I. Inoculation of treixadura musts with autochthonous Saccharomyces cerevisiae strains: Fermentative performance and influence on the wine characteristics. Food Sci. Technol. Int. 2013, 19, 177-186. [CrossRef]

7. Tello, J.; Cordero-Bueso, G.; Aporta, I.; Cabellos, J.M.; Arroyo, T. Genetic diversity in commercial wineries: Effects of the farming system and vinification management on wine yeasts. J. Appl. Microbiol. 2011, 112, 302-315. [CrossRef]

8. Martiniuk, J.T.; Pacheco, B.; Russell, G.; Tong, S.; Backstrom, I.; Measday, V. Impact of commercial strain use on saccharomyces cerevisiae population structure and dynamics in pinot noir vineyards and spontaneous fermentations of a Canadian winery. PLoS ONE 2016, 11, e0160259. [CrossRef]

9. Guzzon, R.; Widmann, G.; Settanni, L.; Malacarne, M.; Francesca, N.; Larcher, R. Evolution of yeast populations during different biodynamic winemaking processes. S. Afr. J. Enol. Vitic. 2011, 32, 242-250. [CrossRef]

10. Cocolin, L.; Heisey, A.; Mills, D.A. Direct identification of the indigenous yeasts in commercial wine fermentations. Am. J. Enol. Vitic. 2001, 52, 49-53.

11. Fleet, G.H. Wine yeasts for the future. FEMS Yeast Res. 2008, 8, 979-995. [CrossRef]

12. Tofalo, R.; Perpetuini, G.; Schirone, M.; Fasoli, G.; Aguzzi, I.; Corsetti, A.; Suzzi, G. Biogeographical characterization of Saccharomyces cerevisiae wine yeast by molecular methods. Front. Microbiol. 2013, 4, 166. [CrossRef]

13. Capece, A.; Romaniello, R.; Siesto, G.; Romano, P. Diversity of saccharomyces cerevisiae yeasts associated to spontaneously fermenting grapes from an Italian "heroic vine-growing area". Food Microbiol. 2012, 31, 159-166. [CrossRef] [PubMed]

14. Lambrechts, M.G.; Pretorius, I.S. Yeast and its importance to wine aromaA review. S. Afr. J. Enol. Vitic. 2000, 21, 97-129.

15. Fleet, G.H. Yeast interactions and wine flavour. Int. J. Food Microbiol. 2003, 86, 11-22. [CrossRef]

16. Romano, P.; Fiore, C.; Paraggio, M.; Caruso, M.; Capece, A. Function of yeast species and strains in wine flavour. Int. J. Food Microbiol. 2003, 86, 169-180. [CrossRef]

17. Sannino, C.; Francesca, N.; Corona, O.; Settanni, L.; Cruciata, M.; Moschetti, G. Effect of the natural winemaking process applied at industrial level on the microbiological and chemical characteristics of wine. $J$. Biosci. Bioeng. 2013, 116, 347-356. [CrossRef]

18. Tufariello, M.; Chiriatti, M.A.; Grieco, F.; Perrotta, C.; Capone, S.; Rampino, P.; Tristezza, M.; Mita, G.; Grieco, F. Influence of autochthonous Saccharomyces cerevisiae strains on volatile profile of Negroamaro wines. LWT Food Sci. Technol. 2014, 58, 35-48. [CrossRef]

19. Tofalo, R.; Patrignani, F.; Lanciotti, R.; Perpetuini, G.; Schirone, M.; Di Gianvito, P.; Pizzoni, D.; Arfelli, G.; Suzzi, G. Aroma profile of montepulciano d'abruzzo wine fermented by single and co-culture starters of autochthonous Saccharomyces and non-Saccharomyces yeasts. Front. Microbiol. 2016, 7, 610. [CrossRef]

20. Nisiotou, A.; Sgouros, G.; Mallouchos, A.; Nisiotis, C.S.; Michaelidis, C.; Tassou, C.; Banilas, G. The use of indigenous Saccharomyces cerevisiae and Starmerella bacillaris strains as a tool to create chemical complexity in local wines. Food Res. Int. 2018, 111, 498-508. [CrossRef]

21. Drumonde-Neves, J.; Franco-Duarte, R.; Vieira, E.; Mendes, I.; Lima, T.; Schuller, D.; Pais, C. Differentiation of saccharomyces cerevisiae populations from vineyards of the azores archipelago: Geography vs Ecology. Food Microbiol. 2018, 74, 151-162. [CrossRef]

22. Goddard, M.R.; Anfang, N.; Tang, R.; Gardner, R.C.; Jun, C. A distinct population of Saccharomyces cerevisiae in New Zealand: Evidence for local dispersal by insects and human-aided global dispersal in oak barrels. Environ. Microbiol. 2010, 12, 63-73. [CrossRef]

23. Beltran, G.; Torija, M.J.; Novo, M.; Ferrer, N.; Poblet, M.; Guillamón, J.M.; Rozs, N.; Mas, A. Analysis of yeast populations during alcoholic fermentation: A six year follow-up study. Syst. Appl. Microbiol. 2002, 25, 287-293. [CrossRef]

24. Santamaría, P.; Garijo, P.; López, R.; Tenorio, C.; Gutiérrez, A.R. Analysis of yeast population during spontaneous alcoholic fermentation: Effect of the age of the cellar and the practice of inoculation. Int. J. Food Microbiol. 2005, 103, 49-56. [CrossRef]

25. Scholl, C.M.; Morgan, S.C.; Stone, M.L.; Tantikachornkiat, M.; Neuner, M.; Durall, D.M. Composition of Saccharomyces cerevisiae strains in spontaneous fermentations of Pinot Noir and Chardonnay. Aust. J. Grape Wine Res. 2016, 22, 384-390. [CrossRef] 
26. Morgan, S.C.; Scholl, C.M.; Benson, N.L.; Stone, M.L.; Durall, D.M. Sulfur dioxide addition at crush alters Saccharomyces cerevisiae strain composition in spontaneous fermentations at two Canadian wineries. Int. J. Food Microbiol. 2017, 244, 96-102. [CrossRef] [PubMed]

27. Blanco, P.; Orriols, I.; Losada, A. Survival of commercial yeasts in the winery environment and their prevalence during spontaneous fermentations. J. Ind. Microbiol. Biotechnol. 2011, 38, 235-239. [CrossRef] [PubMed]

28. Hall, B.; Durall, D.M.; Stanley, G. Population dynamics of Saccharomyces cerevisiae during spontaneous fermentation at a British Columbia winery. Am. J. Enol. Vitic. 2011, 62, 66-72. [CrossRef]

29. Lange, J.N.; Faasse, E.; Tantikachornkiat, M.; Gustafsson, F.S.; Halvorsen, L.C.; Kluftinger, A.; Ledderhof, D.; Durall, D.M. Implantation and persistence of yeast inoculum in Pinot noir fermentations at three Canadian wineries. Int. J. Food Microbiol. 2014, 180, 56-61. [CrossRef]

30. de Celis, M.; Ruiz, J.; Martín-Santamaría, M.; Alonso, A.; Marquina, D.; Navascués, E.; Gómez-Flechoso, M.; Belda, I.; Santos, A. Diversity of Saccharomyces cerevisiae yeasts associated to spontaneous and inoculated fermenting grapes from Spanish vineyards. Lett. Appl. Microbiol. 2019, 68, 580-588. [CrossRef]

31. Schuller, D.; Alves, H.; Dequin, S.; Casal, M. Ecological survey of Saccharomyces cerevisiae strains from vineyards in the Vinho Verde Region of Portugal. FEMS Microbiol. Ecol. 2005, 51, 167-177. [CrossRef]

32. Schuller, D.; Cardoso, F.; Sousa, S.; Gomes, P.; Gomes, A.C.; Santos, M.A.S.; Casal, M. Genetic diversity and population structure of Saccharomyces cerevisiae strains isolated from different grape varieties and winemaking regions. PLoS ONE 2012, 7, e32507. [CrossRef] [PubMed]

33. Di Maio, S.; Polizzotto, G.; Di Gangi, E.; Foresta, G.; Genna, G.; Verzera, A.; Scacco, A.; Amore, G.; Oliva, D. Biodiversity of indigenous Saccharomyces populations from old wineries of South-Eastern Sicily (Italy): Preservation and economic potential. PLoS ONE 2012, 7, e30428. [CrossRef]

34. Viel, A.; Legras, J.L.; Nadai, C.; Carlot, M.; Lombardi, A.; Crespan, M.; Migliaro, D.; Giacomini, A.; Corich, V. The geographic distribution of Saccharomyces cerevisiae isolates within three Italian neighboring winemaking regions reveals strong differences in yeast abundance, genetic diversity and industrial strain dissemination. Front. Microbiol. 2017, 8, 1595. [CrossRef] [PubMed]

35. Valero, E.; Cambon, B.; Schuller, D.; Casal, M.; Dequin, S. Biodiversity of saccharomyces yeast strains from grape berries of wine-producing areas using starter commercial yeasts. FEMS Yeast Res. 2007, 7, 317-329. [CrossRef]

36. Versavaud, A.; Courcoux, P.; Roulland, C.; Dulau, L.; Hallet, J.N. Genetic diversity and geographical distribution of wild Saccharomyces cerevisiae strains from the wine-producing area of Charentes, France. Appl. Environ. Microbiol. 1995, 61, 3521-3529. [CrossRef]

37. Gayevskiy, V.; Goddard, M.R. Geographic delineations of yeast communities and populations associated with vines and wines in New Zealand. ISME J. 2012, 6, 1281-1290. [CrossRef]

38. Knight, S.; Goddard, M.R. Quantifying separation and similarity in a Saccharomyces cerevisiae metapopulation. ISME J. 2015, 9, 361-370. [CrossRef]

39. Morrison-Whittle, P.; Goddard, M.R. From vineyard to winery: A source map of microbial diversity driving wine fermentation. Environ. Microbiol. 2018, 20, 75-84. [CrossRef] [PubMed]

40. Bokulich, N.A.; Thorngate, J.H.; Richardson, P.M.; Mills, D.A. Microbial biogeography of wine grapes is conditioned by cultivar, vintage, and climate. Proc. Natl. Acad. Sci. USA 2014, 111, E139-E148. [CrossRef]

41. Bokulich, N.; Collins, T.; Masarweh, C.; Allen, G.; Heymann, H.; Ebeler, S.E.; Mills, D.A. Associations among wine grape microbiome, metabolome, and fermentation behavior suggest microbial contribution to regional wine characteristics. MBio 2016, 7, e00631-16. [CrossRef]

42. Pinto, C.; Pinho, D.; Cardoso, R.; Custódio, V.; Fernandes, J.; Sousa, S.; Pinheiro, M.; Egas, C.; Gomes, A.C. Wine fermentation microbiome: A landscape from different Portuguese wine appellations. Front. Microbiol. 2015, 6, 905. [CrossRef]

43. CRAEGA Estadísticas. Memoria Anual de Actividades do ano 2018 do Consello Regulador da Agricultura Ecolóxica de Galicia; CRAEGA: Lugo, Spain, 2019; pp. 1-16.

44. Longo, E.; Cansado, J.; Agrelo, D.; Villa, T.G. Effect of climatic conditions on yeast diversity in grape musts from Northwest Spain. Am. J. Enol. Vitic. 1991, 42, 141-144.

45. Lema, C.; Garcia-Jares, C.; Orriols, I.; Angulo, L. Contribution of Saccharomyces and non-Saccharomyces populations to the production of some components of Albariño wine aroma. Am. J. Enol. Vitic. 1996, 47, 206-216. 
46. Blanco, P.; Ramilo, A.; Cerdeira, M.; Orriols, I. Genetic diversity of wine Saccharomyces cerevisiae strains in an experimental winery from Galicia (NW Spain). Antonie Van Leeuwenhoek Int. J. Gen. Mol. Microbiol. 2006, 89, 351-357. [CrossRef]

47. Castrillo, D.; Rabuñal, E.; Neira, N.; Blanco, P. Yeast diversity on grapes from Galicia, NW Spain: Biogeographical patterns and the influence of the farming system. Oeno One 2019, 53, 573-587. [CrossRef]

48. Pallmann, C.L.; Brown, J.A.; Olineka, T.L.; Cocolin, L.; Mills, D.A.; Bisson, L.F. Use of WL medium to profile native flora fermentations. Am. J. Enol. Vitic. 2001, 52, 198-203.

49. Heard, G.M.; Fleet, G.H. Evaluation of selective media for enumeration of yeasts during wine fermentation. J. Appl. Bacteriol. 1986, 60, 477-481. [CrossRef]

50. Querol, A.; Barrio, E.; Huerta, T.; Ramon, D. Molecular monitoring of wine fermentations conducted by active dry yeast strains. Appl. Environ. Microbiol. 1992, 58, 2948-2953. [CrossRef]

51. Maqueda, M.; Zamora, E.; Álvarez, M.L.; Ramírez, M. Characterization, ecological distribution, and population dynamics of saccharomyces sensu stricto killer yeasts in the spontaneous grape must fermentations of Southwestern Spain. Appl. Environ. Microbiol. 2012, 78, 735-743. [CrossRef]

52. Shannon, C.E. A mathematical theory of communication. SIGMOBILE Mob. Comput. Commun. Rev. 2001, 5, 3-55. [CrossRef]

53. Simpson, E.H. Measurement of diversity. Nature 1949, 163, 688. [CrossRef]

54. Pielou, E.C. An Introduction to Mathematical Ecology; Wiley: New York, NY, USA, 1969.

55. Anderson, M.J.; Walsh, D.C.I. PERMANOVA, ANOSIM, and the Mantel test in the face of heterogeneous dispersions: What null hypothesis are you testing? Published by: Ecological Society of America linked references are available on JSTOR for this article: Your use of the JSTOR archi. Ecol. Monogr. 2013, 83, 557-574. [CrossRef]

56. Clarke, K.R. Non-parametric multivariate analyses of changes in community structure. Aust. J. Ecol. 1993, 18, 117-143. [CrossRef]

57. Anderson, M.J. A new method for non-parametric multivariate analysis of variance. Austral Ecol. 2001, 26, $32-46$.

58. Torija, M.J.; Rozès, N.; Poblet, M.; Guillamón, J.M.; Mas, A. Yeast population dynamics in spontaneous fermentations: Comparison between two different wine-producing areas over a period of three years. Antonie Van Leeuwenhoek Int. J. Gen. Mol. Microbiol. 2001, 79, 345-352. [CrossRef]

59. Cordero-Bueso, G.; Arroyo, T.; Serrano, A.; Valero, E. Influence of different floor management strategies of the vineyard on the natural yeast population associated with grape berries. Int. J. Food Microbiol. 2011, 148, 23-29. [CrossRef]

60. Börlin, M.; Venet, P.; Claisse, O.; Salin, F.; Legras, J.L.; Masneuf-Pomarede, I. Cellar-associated Saccharomyces cerevisiae population structure revealed high-level diversity and perennial persistence at Sauternes wine estates. Appl. Environ. Microbiol. 2016, 82, 2909-2918. [CrossRef]

61. Santamaría, P.; López, R.; López, E.; Garijo, P.; Gutiérrez, A.R. Permanence of yeast inocula in the winery ecosystem and presence in spontaneous fermentations. Eur. Food Res. Technol. 2008, 227, 1563-1567. [CrossRef]

62. Zhang, H.Y.; Lee, S.A.; Bradbury, J.E.; Warren, R.N.; Sheth, H.; Hooks, D.O.; Richards, K.D.; Gardner, R.C. Yeasts isolated from New Zealand vineyards and wineries. Aust. J. Grape Wine Res. 2010, 16, 491-496. [CrossRef]

63. Blanco, P.; Mirás-Avalos, J.M.; Orriols, I. Effect of must characteristics on the diversity of Saccharomyces strains and their prevalence in spontaneous fermentations. J. Appl. Microbiol. 2012, 112, 936-944. [CrossRef]

64. Ciani, M.; Capece, A.; Comitini, F.; Canonico, L.; Siesto, G.; Romano, P. Yeast interactions in inoculated wine fermentation. Front. Microbiol. 2016, 7, 555. [CrossRef] [PubMed]

65. Pérez, F.; Ramírez, M.; Regodón, J.A. Influence of killer strains of Saccharomyces cerevisiae on wine fermentation. Antonie Van Leeuwenhoek Int. J. Gen. Mol. Microbiol. 2001, 79, 393-399. [CrossRef]

66. Cocolin, L.; Pepe, V.; Comitini, F.; Comi, G.; Ciani, M. Enological and genetic traits of Saccharomyces cerevisiae isolated from former and modern wineries. FEMS Yeast Res. 2004, 5, 237-245. [CrossRef] [PubMed]

67. Ciani, M.; Mannazzu, I.; Marinangeli, P.; Clementi, F.; Martini, A. Contribution of winery-resident Saccharomyces cerevisiae strains to spontaneous grape must fermentation. Antonie Van Leeuwenhoek Int. J. Gen. Mol. Microbiol. 2004, 85, 159-164. [CrossRef] 
68. Knight, S.; Klaere, S.; Fedrizzi, B.; Goddard, M.R. Regional microbial signatures positively correlate with differential wine phenotypes: Evidence for a microbial aspect to terroir. Sci. Rep. 2015, 5, 114233. [CrossRef]

69. Vigentini, I.; De Lorenzis, G.; Fabrizio, V.; Valdetara, F.; Faccincani, M.; Panont, C.A.; Picozzi, C.; Imazio, S.; Failla, O.; Foschino, R. The vintage effect overcomes the terroir effect: A three year survey on the wine yeast biodiversity in Franciacorta and Oltrepò Pavese, two northern Italian vine-growing areas. Microbiol. 2015, 161, 362-373. [CrossRef] [PubMed]

70. Sabate, J.; Cano, J.; Querol, A.; Guillamón, J.M. Diversity of Saccharomyces strains in wine fermentations: Analysis for two consecutive years. Lett. Appl. Microbiol. 1998, 26, 452-455. [CrossRef] [PubMed]

71. Castrillo Cachón, D. Estudio de la diversidad de levaduras en uva de cultivo ecológico y convencional en Galicia: Patrones biogeográficos e influencia en las características químicas y sensoriales del vino. Ph. D. Thesis, University of León, León, Spain, 2018.

72. Callejon, R.M.; Clavijo, A.; Ortigueira, P.; Troncoso, A.M.; Paneque, P.; Morales, M.L. Volatile and sensory profile of organic red wines produced by different selected autochthonous and commercial Saccharomyces cerevisiae strains. Anal. Chim. Acta 2010, 660, 68-75. [CrossRef]

73. Blanco, P.; Mirás-Avalos, J.M.; Pereira, E.; Orriols, I. Fermentative aroma compounds and sensory profiles of Godello and Albariño wines as influenced by Saccharomyces cerevisiae yeast strains. J. Sci. Food Agric. 2013, 93, 2849-2857. [CrossRef]

(C) 2020 by the authors. Licensee MDPI, Basel, Switzerland. This article is an open access article distributed under the terms and conditions of the Creative Commons Attribution (CC BY) license (http://creativecommons.org/licenses/by/4.0/). 